\section{artelogie}

\section{Artelogie}

Recherche sur les arts, le patrimoine et la littérature de I'Amérique latine

16 | 2021

Fotografía y migraciones, siglos XIX-XXI.

\title{
El testamento del Abate Louis Comte
}

\section{Edgard Vidal}

\section{OpenEdition}

Journals

\section{Edición electrónica}

URL: https://journals.openedition.org/artelogie/9102

DOI: 10.4000/artelogie.9102

ISSN: 2115-6395

\section{Editor}

Association ESCAL

\section{Referencia electrónica}

Edgard Vidal, «El testamento del Abate Louis Comte», Artelogie [En línea], 16 | 2021, Publicado el 27 enero 2021, consultado el 03 septiembre 2021. URL: http://journals.openedition.org/artelogie/9102 ; DOI: https://doi.org/10.4000/artelogie.9102

Este documento fue generado automáticamente el 3 septiembre 2021.

Association ESCAL 


\title{
El testamento del Abate Louis Comte
}

\author{
Edgard Vidal
}

1 El 3 de julio de 1839 delante de la Cámara de Diputados y el 19 de agosto delante de la Academia de Ciencias, Don François Arago daba a conocer la invención de Daguerre, bajo la presidencia del Rey Louis-Philippe Ier. En este discurso, la fotografía era un proceso que permitía a todo hombre llevar rápidamente a cabo tareas científicas y artísticas. Añade que de otra manera serían necesarios "decenas de años y legiones de dibujantes", mientras que con "el daguerrotipo, un hombre podía llevar a cabo esta obra inmensa ". Una gran invención entonces, que Francia, dijo, quería "dar liberalmente a todo el mundo" (Arago François, 1839 : 52). Es con estas ideas liberales (de una liberalidad muy francesa, porque los estados europeos jugarían un gran rol en su difusión, como lo veremos más tarde) que hace exactamente 178 años llegaba a América Latina la fragata "L'orientale" a las costas atlánticas. Su misión entre otras, difundir el daguerrotipo, y para esto dar la vuelta al mundo, pasando por las costas atlánticas y pacificas de América Latina.

2 La historia es conocida y ya fue descrita en varios artículos y libros, de los cuales el pionero de Adrian Carré (1970 : 17-35) y los posteriores de Derek Wood (1996 : 113-118) ${ }^{1}$ y de Maria Inez Turazzi (2011, p. 45-62). Esta última autora ha actualizado y ampliado muy recientemente su trabajo en $2019^{2}$. El presente texto, con el análisis del testamento de Louis Comte, fue presentado en febrero 2018, a la comunidad científica de América Latina y Europa, reunida en la bella Università di Ca'Foscari de Venezia ${ }^{3}$. Después, ha sido muy difundido a colegas y amigos, estimulando nuevas preguntas sobre el tema y es publicado en español, por la primera vez en este número, que se hace eco del coloquio. De este modo que, para situar al lector, solo haremos una rápida introducción sobre este viaje (en particular para entender su función política en Europa) y luego nos centraremos en la figura del daguerrotipista mayor de la misión, para intentar comprender, a partir de estos documentos sus actividades y acciones en una ciudad de Montevideo en guerra, sitiado por las tropas de Rosas y Oribe.

3 Nuestra investigación, busca sobretodo desvelar un aspecto importante de la biografía del prelado Louis Comte, miembro del equipaje y designado por el gobierno francés para comercializar la nueva técnica fotográfica. La traza del abate francés, rastreada 
con suceso en Montevideo por el interesante libro coordinado por Magdalena Broquetas $^{4}$, se pierde cuando éste parte del Río de la Plata. Traemos aquí algunas huellas de su vida posterior a su estadía en América Latina, hasta ahora poco exploradas y en el cual se muestra que el abate continua teniendo fuertes lazos con Montevideo. Y que además logra traer a Francia desde esta pequeña ciudad del sur, una cuantiosa fortuna. ¿ De donde provenía la misma? No podremos responder a ésta pregunta pero si, al menos, intentar acercarnos a éste enigma (iluminando de otra manera el período montevideano del prelado), que es también un curioso capitulo económico de la cultura uruguaya y de la historia de esta técnica. sujeto en particular los trabajos también preliminares de Jacinto Duarte para el inicio del cine y de la publicidad en Uruguay y los ya citados del grupo de Magdalena Broquetas), analizaremos la repercusión del daguerrotipo introducido por este hombre de iglesia en la región (Rio de la Plata), en términos mediáticos e históricos en un contexto particular de la vida geopolítica de la región ${ }^{5}$. En efecto, entre el 10 de marzo de 1839 y el 8 de octubre de 1851 en el Río de la Plata, acaece el sitio de Montevideo. Al origen, una guerra civil de la Provincia Oriental del río, que se transformó en un conflicto regional con la intervención de Argentina y Brasil. Este evento también adquirió una dimensión internacional cuando Francia, Gran Bretaña y fuerzas extranjeras se unieron a la lucha.

- Finalmente terminaremos con un detallado desglose del testamento de Comte.

Porque a partir de la vuelta a Europa del Abate, uno de los iniciadores de la fotografía en América Latina, perdemos toda traza de él. Este artículo pretende aportar informaciones sobre este período de la historia, gracias al análisis de su legado, donde afirma recibir una importante suma de dinero por medio de una trasferencia desde Montevideo. Terminaremos incursionando en un examen del documento hallado, con el objetivo de profundizar las reflexiones relativas a lo que algunos críticos llaman la primera experiencia "open source" (Gunthert André, 2006 : 1), dada la importancia de esta técnica y del estado francés en su impulso.

\section{El Abate Comte}

Recordemos la primera parte más conocida de las aventuras del francés. Comte había navegado a América del Sur en una expedición L'Orientale que salió de Francia a fines de septiembre de 1839. El viaje del navío, en la cual Comte, dio la primera demostración del daguerrotipo en América del Sur, había sido organizado a lo largo del primer semestre de 1839 por el capitán Auguste Lucas. El proyecto era de crear un navíouniversidad, donde los jóvenes seguirían cursos universitarios, al mismo tiempo que adquirirían, por exploración de las diversas partes del globo, conocimiento positivo de todo lo relacionado con la marina y los intereses comerciales. 
10 En este primer tema ya trabajado por sendos libros y artículos, no agregaríamos gran cosa sino remarcar, el espíritu de emprendimiento de todos los participantes a la aventura inclusive sin duda nuestro párroco. Por ejemplo el texto publicado en el periódico (Le Constitutionnel, 1839 : 6) justifica las razones (morales) de tal empresa. Esta larga excursión no tendrá como único deseo el de satisfacer los sentimientos de curiosidad. Hay aquí un objetivo afirmado, conduciendo a mejoras comerciales importantes. Preparará Francia para luchar con mayor éxito contra las potencias que compiten con ella o que se han asegurado una superioridad marítima incontestable, esto claro está, en el contexto de la expansión europea protagonizada por Gran Bretaña, Alemania y Francia.

11 El interés de volver sobre éste tema del viaje de l'Orientale, tan escrito desde los trabajos inaugurales de Adrian Carré, es insertarlo en el periodo histórico que va desde lo que se llamó "La Monarchie de Juillet" hasta la Revolución de 1848, pero que en lo económico, hará entrar Francia definitivamente en la era industrial, insertándola en un movimiento de mundialización importante. Los puntos comunes entre expansión comercial e innovación tecnológica, están siempre presentes y es necesario comprenderlos también en el dominio cultural. En ese sentido el siglo XIX que finaliza con una síntesis creativa completada por el período llamado Belle époque, permite ir más allá del anterior sistema técnico basado en particular en la máquina de vapor, el carbón y el hierro, dando más tarde una fuerza inédita con sus inventos (del cual el aparato creado por Daguerre es un ejemplo emblemático), en particular la electricidad, a las tecnologías de la imagen y del conocimiento.

12 Louis Comte se registra como capellán en el barco y profesor de música de los numerosos alumnos que fueron aceptados (previo pago, como lo hemos visto más arriba) a partir de los 12 años. En América del Sur, los informes sobre el primer daguerrotipista, no hablan de Comte más de " Combes " (así Machado de Assis ver más abajo). Incluso ya finalizado el siglo XX, Boris Kossoy, en su clásico libro Fotografia $E$ Historia, lo llama "Louis Compte" (Kossoy, 2003:109). Se sabe que Louis Comte nació en Nantes, el 3 de junio de 1798, pero después de haber vivido durante muchos años en el otro lado de Francia en La Grande-Verrière, un pequeño pueblo cerca de Autun. En esta ciudad siguió el seminario donde se formó como Abate.

13 No sabemos aún exactamente cuantos daguerrotipos traía L'Orientale pero es seguro que había una cantidad importante, porque en cada puerto de América que visitaba vendía o daba algún ejemplar : el futuro emperador Pedro I en Rio de Janeiro, el mismo Comte en Montevideo se quedo con otros y muy posiblemente le vendió uno ya en Montevideo al pintor Amadeo Gras. Alcanzó también para que otra nave francesa, la Justine, se embarque desde Valparaíso (donde se hundió "L'Orientale ») y llegando a Sídney , pusiera aparatos a la venta en abril de 1841 (ver mas abajo).

14 Luego de la llegada a Rio de Janeiro (presenciada por Machado de Assis quien contó, el 7 de agosto de 1864, como editor de la Revista de Río de Janeiro, la historia de la introducción del daguerrotipo en Brasil) la fragata francesa sale de la entonces capital del Brasil , no antes que el consejero científico de la expedición - Soulier de Sauve ${ }^{6}$ - y su esposa se quedasen en éste país.

15 Antes de que el buque prosiga su viaje desde Montevideo a Chile, Comte renuncia al viaje quedándose en Montevideo. Buenos Aires fue sitiada por la Marina francesa y Valparaíso era el puerto habitual de quien quería cruzar el Pacífico. Por último, cuando 
salía de Valparaíso, la fragata se hundió, poniendo fin a las promesas de un viaje memorable de circunnavegación.

Los primeros avisos relacionados al daguerrotipo en la prensa montevideana fueron aquellos en los que Louis Comte ofrecía aparatos en venta, y se comprometía con sus clientes a "enseñarles su mecanismo", con la expectativa de salvar las dificultades en su manejo que podían disuadir a los posibles compradores de adquirir uno. En el texto de El Nacional, publicado en Montevideo el 6 de marzo de 1841, Comte se presenta relacionado directamente con "M.Daguerre quien me ha instruido en el manejo de su instrumento y con los mejores ópticos de Paris que la fabrican ». Se remarca también que la fotografía proporciona goces y es producto de fuertes deseos pero también temor por su novedad y su posible dificultad de uso. Que el Abate tiene en su poder las ultimas versiones del producto con mejoras.

Que él puede enseñar su uso, une especie de servicio de post-venta avant la lettre. Que funciona como un servicio de comercios del Consulado Francés. Que también ofrece servicios adicionales que son las vistas y las clases de dibujo gracias a la técnica fotográfica (Aviso El Nacional, Montevideo, 6 de marzo de 1841) 7 .

\section{Porqué las vistas?}

Con la llegada del daguerrotipo confluyeron en Montevideo diferentes formas de representación iconográfica. Entre las técnicas pictóricas predominaban el óleo y la miniatura, que se utilizaban en general para realizar retratos por encargo. La acuarela y el dibujo a lápiz o carbonilla eran las técnicas más comunes con que se realizaban las vistas y paisajes. Estas imágenes eran en general producidas por viajeros, e inspiraban reproducciones al grabado que eran comercializadas en sus países de origen o en algunos casos también en Montevideo. Con ellas también se hacían espectáculos visuales, denominados "viaje de ilusión" o "gabinete óptico". Estos se realizaban una vez por semana, ofreciendo alrededor de una decena de imágenes de edificios y paisajes, y de escenas históricas entre las que había principalmente episodios bélicos de la historia europea. Con el daguerrotipo (se sabe que Daguerre es también inventor del diorama) se agrega éste nuevo procedimiento al espectáculo, con gran éxito en Montevideo durante largo tiempo, como lo muestran los siguientes anuncios publicados en el Río de la Plata.

El 16 de febrero de 1848, en "Comercio del Plata" apareció este otro anuncio ("Viaje de Ilusión", El Nacional, Montevideo, 17 de octubre de $1842^{8}$ ) de un espectáculo donde se muestran paisajes de diferentes lugares del mundo. Es importante remarcar como las vistas se constituyen en una primera forma de mundialización del imaginario en el contexto como hemos dicho de una guerra internacional alrededor de lo que es llamado el Sitio Grande de Montevideo. En el anuncio se prometen lugares tales que Génova, Plaza "Vandoma" con monumento a Napoléon, el Vesubio y su explosión en Italia el 22 de octubre de 1822, el "Lubre" (Louvre) en Paris, la plaza vieja de la Habana, una vista de Barcelona, el fuerte real de San Pedro de La Martinica pero también la plaza de Matriz de Montevideo el 12 de junio de 1842.

21 Aquí en esta ultima vista tendremos también la influencia del daguerrotipo sobre las vistas por la precisión propiamente fotográfica de la descripción: 
"Vista de la Plaza Matriz de Montevideo en el dia 12 de agosto de 1842, en la segunda función que dio la compañía de Gimnástica mirada desde la Matriz." (Duarte Jacinto,1952 : 118)

Ya que hemos visto también en el anterior anuncio que Comte daba cursos de dibujo ayudado sin duda por su técnica fotográfica.

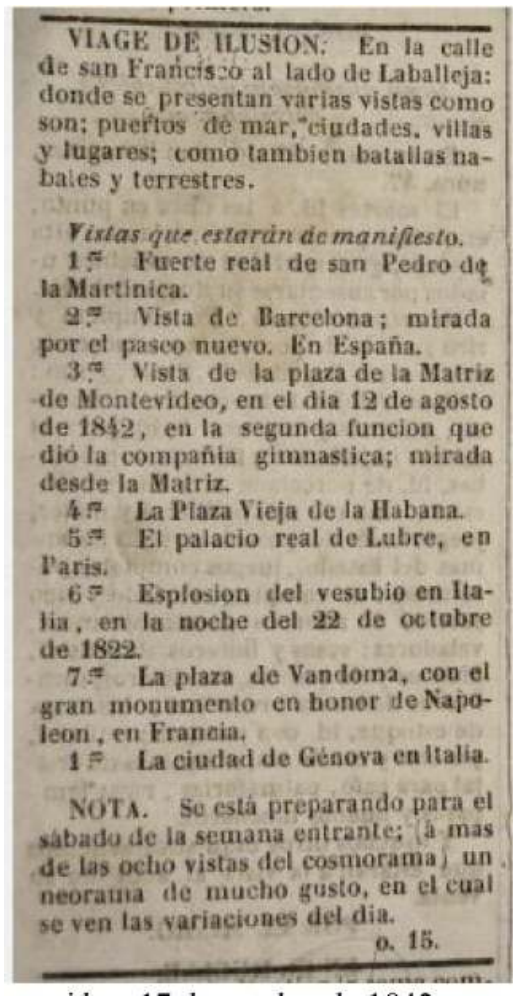

Imagen 1. "Viaje de Ilusión", El Nacional, Montevideo, 17 de octubre de 1842.

Pero es la nota de este aviso de octubre del 42 que indica la influencia de Daguerre y su contacto por su intermediario con Comte : "Se esta preparando...un neorama de mucho gusto, en el cual se ven las variaciones del día"

Tratase sin duda del diorama, una experiencia teatral presentada al público en una sala especialmente diseñada por Daguerre. Lo que había hecho son escenas pintadas por las cuales los espectadores podían contemplar una pintura de paisaje cuya apariencia cambiaba de una manera a veces sutil, a veces dramática. Escenas pintadas $(7 \mathrm{~m}$ de ancho y $6.5 \mathrm{~m}$ de alto) a mano en un lienzo. La característica particular de este espectáculo era justamente que dependiendo de la intensidad, la dirección de la luz y de los movimientos de los operadores la escena parecía cambiar.

Esta clase de espectáculos, anuncia el cinematógrafo, y aunque la promoción se refiere a "vistas fijas", en algunos casos se mueven, como lo menciona el aviso que sigue, aparecido en 1840.

"NUEVO GABINETE :Pintoresco y Mecánico calle del Rincón 182 saliendo de la Plaza Matriz. El propietario de este gabinete estando por dejar la capital avisa al respetable público que desde hoy estarán de manifiesto las siguientes vistas: 
1 - La Gran Montaña de S. Bernardo, cubierta de nieve, por donde se verá la pasada de Napoleón a la cabeza de su ejército de artillería, infantería, tren del ejército. Todo con sus movimientos naturales.

2 - Vistas del pueblo de Génoba al ponerse el sol.

3 - La hermosa Catedral de Milán, una de las maravillas del mundo donde se verá la pasada de la gran Guardia acompañada de la música en el palacio del Virrey, efecto de día.

Los precios serán 1er, puesto con asiento 12 vintenes, 2do. puesto con asiento 8 vintenes. Se dará principio a las 8 hs en punto."( Duarte Jacinto, 1952 :118) mundo". Fue función que había establecido en París y en el que tenía la intención de mostrar las imágenes públicas del mundo. Grandes pinturas, que representaban los sitios y monumentos notables de todas partes del mundo. Las pinturas estaban brillantemente iluminadas por lámparas, y los lentes e instrumentos ópticos les daban un tamaño real. Estas informaciones nos parecen muy importantes porque comercializar esta nueva industria no era solo vender el daguerrotipo sino que había toda una serie de servicios y productos asociados que terminaron siendo muy rentables.

31 La prehistoria del cine como industria cultural en Uruguay a través de la animación de las vistas (nos referimos en particular a este momento que va de 1840 a 1848) también era redituable de este viaje de L'Oriental y del abate Comte. 


\section{El testamento del abate LoUIS COMTE}

Pero si la estadía del abate en Rio de Janeiro y en Montevideo está correctamente tratada por la historiografía en las ya citadas obras de Maria Inez Turazzi ${ }^{9}$ y de Clara von Sanden ${ }^{10}$ en el trabajo coordinado por Magdalena Broquetas ${ }^{11}$, después de su partida de América Latina las trazas de Louis Comte se borran de los registros. Quisiéramos traer a luz un elemento poco examinado que muestra las ramificaciones e importancia del comercio del daguerrotipo. Louis Comte nació en Nantes el 3 de junio de 1798. Sin embargo, es en la región de Autun, donde su padre Charles Comte (próspero comerciante de Nantes) es originario y donde Louis también asistirá al seminario y recibirá las órdenes (A. Carré, 1970, p. 25.). Hemos visto algunos aspectos de la vida de Comte en Montevideo. Pero a partir de su vuelta a Europa, perdemos toda traza de él hasta encontrar este escrito donde en el año 1864 se declara dueño de una de la propiedades más importantes de Sampans.

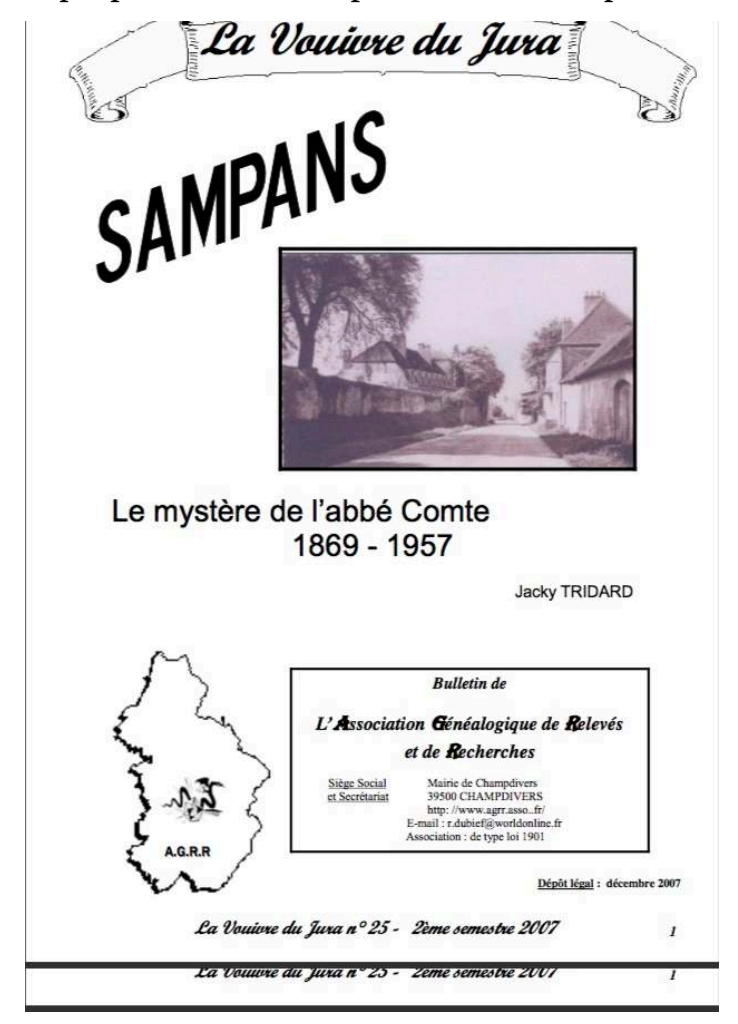

Imagen 2 : La Vouivre du Jura nº 25 - 2ème semestre 2007

También en los archivos de la prensa, en el boletín La Vouivre du Jura n 25 - 2ème semestre 2007, hemos encontrado esta noticia. En él, Louis Comte es visto sólo como un religioso y ningún lazo se establece claro, con nuestro Louis Comte, introductor del daguerrotipo en América Latina. Así el redactor Jacky Tridard, miembro de la "Association Généalogique de Relevés et de Recherches " en su boletín La Vouivre du Jura n 25 - 2ème semestre 2007 se pregunta sin responder :

"¿Qué oportunidad ha sido explotada por nuestra afortunado religioso para comprar en nuestro pueblo esta hermosa propiedad y vivir allí en los últimos años? La respuesta, por el momento está en suspenso, pero al llegar a establecerse en Sampans, él trae consigo los fermentos de una saga familiar digna de las más bellas novelas y que sin duda alimentará con sus historias 
las vigilias del lugar por varias generaciones?."12 (La Vouivre du Jura $\mathrm{n}^{\circ} 25$, $2007: 4)$.

Poco antes de su muerte, nuestro Louis Comte se instala en Sampans, un pueblo de la región del Jura en Francia. ¿Como hizo un prelado, cuyo fin es la religión para ganar esta importante fortuna y poder instalarse en esta magnífica estancia con sus "con sus casas, muebles, terrenos de viñas y jardines", donde viviría sus últimos años, en una fase posterior a la revolución francesa en que la religión pasaba por un importante proceso de secularización y perdía cada vez más su importancia económica ? La respuesta es quizás la riqueza familiar constituida por comerciantes de la ciudad puerto de Nantes. Sin embargo, si leemos atentamente el documento que transcribo, encontramos otros datos interesantes.

Image 105D0CC0000044F300005FA30002AE682F2F8C64.emf

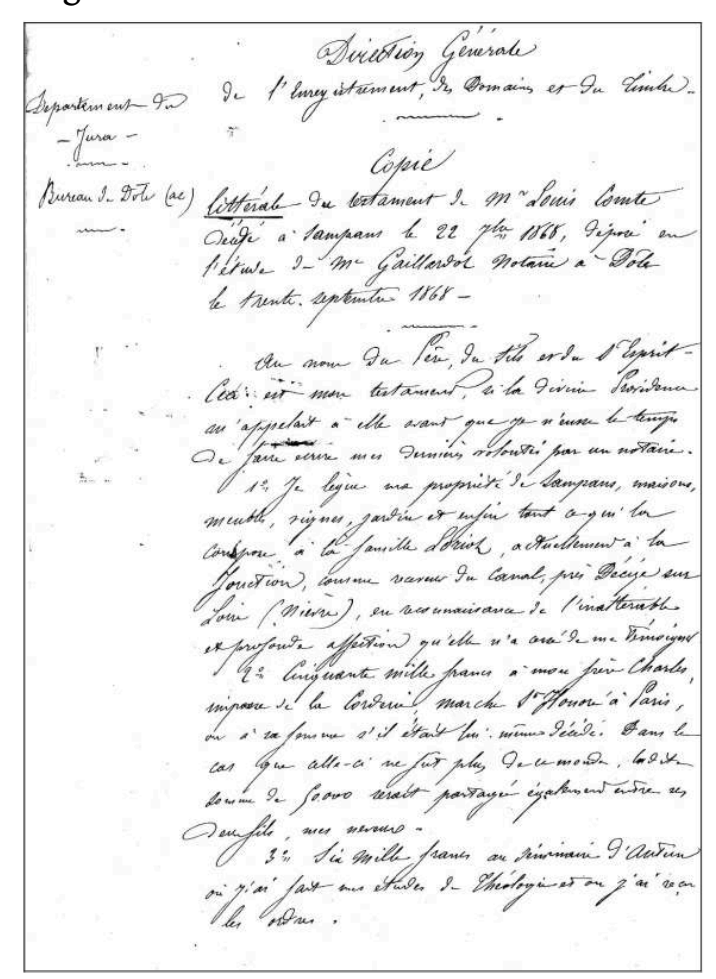

Imagen 3 : Testamento de Louis Comte, muerto a su domicilio de Sampans el 22 de septiembre de 1868.

Aquí pues está a la vista el estado de la herencia de Louis Comte muerto el 09/22/1868 a la edad de 70 años, de acuerdo a su voluntad de fecha 11 de enero 1864, presentado ante el Sr. Galliardot de Dole.

" Decize sur Loire el $1^{\circ}$ de noviembre de 1864.

Lego mi fortuna que consiste en la propiedad de Sampans con,

1. Casas, muebles, jardín, viñedo para la familia LORIOT, inspector del canal cerca de Decize en (Nièvre).

2. 50.000 francos para mi hermano Charles, viviendo en el Impasse de la Corderie en el mercado de París Saint Honoré o a sus herederos, sus dos hijos y mis sobrinos.

3. 60.000 francos al seminario donde hice mis estudios de teología y donde recibí las órdenes.

4. 1.000 francos al hospicio 
5. 5.000 francos a la iglesia de Decize sur Loire.

6. 6.000 francos al seminario para que digan 6.000 misas de las cuales 4.000 que las misas por el eterno descanso de mi alma y 2.000 para el de Rosalie BOSSY, mi buena y tierna madre.

7. 3.000 francos para la oficina de caridad de Sampans.

8. 10.000 francos colocados en pensión estatal. Dicho ingreso se dará toda su vida a la empleada doméstica durante los años que se quedase en casa; y a su muerte volverá a mi sobrino.

9. 8.000 francos a Madame LORIOT de mi familia

10. 4.000 Frs a mi amiga Lazarette REYNAUT del cual el padre es Jean, posadero en el pueblo de Cussy Morvan cerca de Autun.

Después de los gastos funerarios, que será entregado al Sr. LORIOT.

Yo lo nombro como ejecutor junto conmigo en Cussy GILLIOT notario a quien lego mis dos pistolas y todas mis pertenencias y libros."

(Testamento traducido de Louis Comte, muerto a su domicilio de Sampans el 22 de septiembre de 1868) sigue siendo el gran edificio de la Ruta 38 en Dole, con su gran parque cerrado por un muro alto, donde varias puertas dan accesos a la viña, que rodea las actuales urbanizaciones del Monte Roland. Otras casas, tierras y viñedos también se cuentan en esta enorme propiedad de la tierra poseída por el abate y que lega a la familia LORIOT en 1869 .

La voluntad de Louis Comte que muestra el estado de su fortuna, también pone en evidencia los fuertes lazos que lo unen con la región de origen de Autun. El abad deja entonces la finca de Sampans en su totalidad a un único legatario, Euzebe Loriot, inspector del canal a Decize. Es muy probable que Decize sea el lugar, no muy lejano de Sampans y con abundantes vías de agua, donde nuestro abate pasaba sus vacaciones de verano, en un tiempo donde las idas al mar, desde el centro de Francia, no eran accesibles rápidamente.

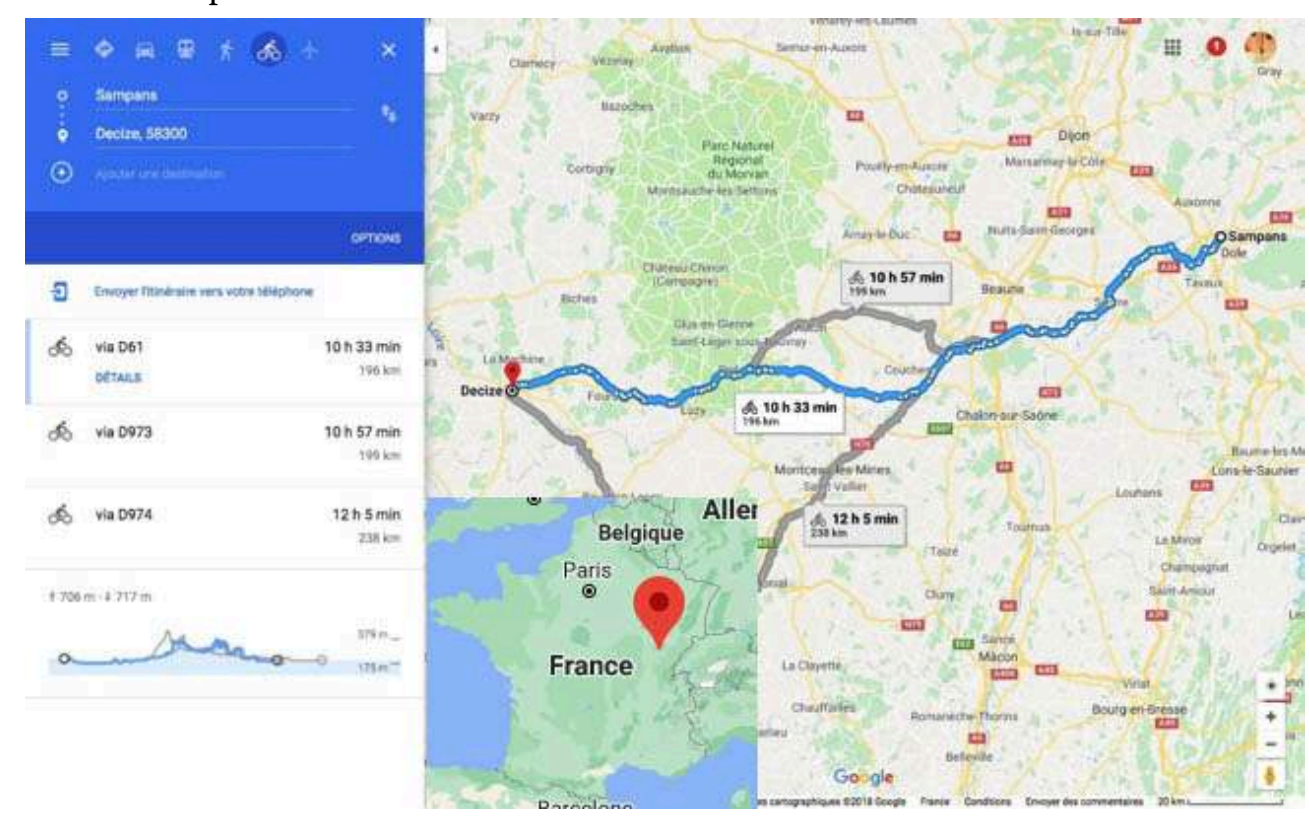

Imagen 4 : Ruta Sampans Decize, 10 horas y media en bicicleta.

Para dar una idea de la importancia de estos bienes podemos afirmar que -según el estudio del censo de población de 1891, citado por el boletín - los herederos vivos 
tenían ingresos (por las tierras y productos de la misma) suficientes para mantener dos hogares, ya que los dos jefes de familia se declaran rentistas.

Extracto del censo de 1891:

- Jean François Beaulieu, de 52 años, rentista, cabeza de familia,

Marie Loriot, de 48 años, su esposa y sus tres hijos.

- viuda Loriot Vuillemin, 49 años, rentista, cabeza de familia, y una hija.

Claro que hasta aquí nada permite afirmar que la fortuna se deba a sus actividades montevideanas, sino fuera porque el testamento no termina allí.

Sigue un poco más abajo la frase siguiente, escrita de la mano de Louis Comte :

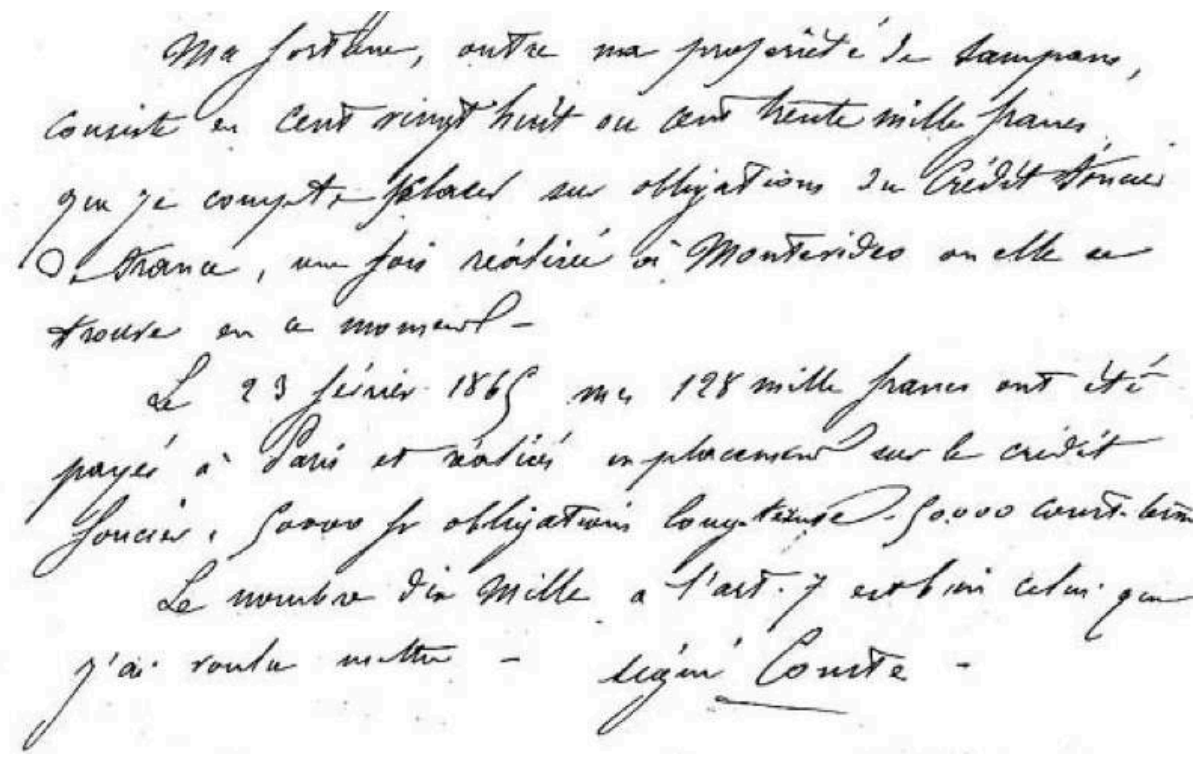

Imagen 5 : Testamento de Louis Comte, fragmento

" Mi fortuna, además de las propiedades de Sampans, se compone de 128.000 a 130.000 francos, que tengo la intención de colocar en la obligación del Crédit Foncier de France, una vez realizada la transferencia desde Montevideo, donde se encuentran ahora".( La Vouivre du Jura, 2007, p.4)

Y agrega el día 29 de febrero de 1865, en el mismo pliego que

"mis 128.000 francos se pagaron en Paris al Crédit Foncier :

50.000 francos en obligación de largo plazo y el resto en obligaciones de corto plazo. Firmado en Dole, BILLAR, Secretario". ( La Vouivre du Jura, 2007, p.4)

Para tener una idea de estos valores hay que pensar por ejemplos en salarios anuales.

El salario promedio aritmético para un hombre sin comida en 1852 es de $1.41 \mathrm{fr}$ por día, lo que significa 423 francos al año (Heffer Jean, Chanut Jean-Marie, Mairesse Jacques, 1986 : pp. 1273-1302- p.1276).

Este dinero recibido de Montevideo equivale entonces a 302 años de un obrero agrícola o 371 años de un cocinero o siguiendo los costo del barco universidad L'Oriental, que hemos visto más arriba ${ }^{13}, 52$ vueltas al mundo (con formación universitaria y teniendo en cuenta lo extraordinario de los transportes mundiales en ese momento!) aproximadamente 

año 1850, para la reconstrucción del Estado Uruguayo reunificado por Francia en el cuadro de los acuerdos que finalizaron el Sitio Grande de Montevideo (1843-1851) (Avenel, Jean-David, 1998 : 114). Vayamos a las más importantes y que parecen mostrar que la economía de esta nueva industria cultural que era el daguerrotipo fue floreciente para nuestra región y esto pese a los períodos de guerra. No es con los cursos de dibujo que el abate pudo juntar tal suma. Se sabe, en cambio, que el daguerrotipo, sus suministros y su producción (en particular los retratos) se vendían a precio de oro.

51 Porque para la obtención de imágenes se necesitaba contar con toda una serie de aparatos (cámara oscura, trípode, caja para el revelado), accesorios (en particular los lentes), productos químicos, etc.. La hipótesis que nos parece más probable, para explicar esta importante suma de dinero, que Louis Comte recoge mucho después de su partida en Uruguay, se debió a la exportación de la industria del daguerrotipo, que desde Montevideo (el bloqueo francés al puerto de Buenos Aires tuvo lugar entre 1838 y 1840 pero se extiende con lo que es considerado el Bloqueo anglo-francés del Río de la Plata durando de 1845 a 1849) se propagó a toda la región, en particular Argentina, de la mano de fotógrafos que como Amadeo Gras, iban de una a otra capital de América Latina (sobretodo Buenos Aires y Santiago de Chile).

52 En este sentido, se contaban por decenas en los primeros años de la década de 1850, el número de fotógrafos trashumantes que realizaba retratos. Entre 1850 y 1854 se encuentran los nombres de Amadeo Gras, Guyot, F. Bernard, Fernando Le Bleu, Charles de Forest Fredericks (solo o en compañía de sus socios, Saturnino Masoni y George Panabert), John G. Case, Alfonso Fermepin y Félix Rossetti (Broquetas Magdalena, 2011 : 44). Quién dice aparatos, dice también suministros como bien se sabe.

53 Como bien lo observa Clara Elisa Von Sanden citando al viajero Xavier Marmier, Montevideo "era el centro de un comercio de importación y de exportación que, desde las fronteras del Paraguay, se extendía hasta los límites septentrionales de Europa" (Von Sanden Clara, $2011: 21$ ).

54 Estos puntos nos permite de relativizar, para concluir, lo que argumenta Clara von Sanden :

\footnotetext{
"Cabe aclarar, sin embargo, que en esta primera etapa, la fotografía se difundió entre un público muy reducido. Además, su alto costo lo convertía en un objeto suntuoso, que sólo quedaba al alcance de los grupos de mayor poder adquisitivo (...) en una crisis económica como la que sufrió el país durante la guerra que estaba en curso y la inmediata pos-guerra, en muchos casos ni aún los sectores más pudientes de la sociedad estaban en condiciones de adquirir objetos de lujo. Por esta razón, no es aventurado pensar que la primera difusión del invento se vio fuertemente mermada por la coyuntura económica." (Von Sanden, $2011: 36)^{14}$
}

55

En efecto, la situación económica de Montevideo era dramática, pero quizás no para todo el mundo. El comercio internacional entre América y Europa continuaba y en medio del caos los testimonios de Sarmiento, que vivió allí entre diciembre de 1845 y fines de enero de 1846, son definitivos : 
"...se introdujeron en 1840 , época del mayor auje de Montevideo, siete millones de mercaderías europeas, que cambiaron por ocho millones cuatrocientos setenta i un mil pesos de productos americanos, dejando al estado, dos millones ochenta i siete mil pesos de renta. Novecientos buques de alta mar entraron en el puerto, $i$ en los primeros nueve i $1 / 2$ meses de 1841, alcanzaron a 856. En 1836, cuando el movimiento principió, entraron 295 buques i salieron 276, que introdujeron tres i medio millones i esportaron una cifra por poco ménos igual. Pero hai una riqueza que no se esporta ni introduce, i esta es la que se crea en todos los grandes focos de comercio i de industria, la cual queda en casas i barrios enteros construidos, en millares de familias establecidas, en pequeñas i grandes fortunas improvisadas" (Sarmiento Domingo Faustino, $1851: 23$ ).

Habría que agregar entonces estos dos elementos :

Lo primero, es la diversificación de la(s) industria(s) de Daguerre. No solo se trata de comercializar los aparatos pero también los espectáculos y vistas, que hemos observado más arriba, serían una forma original del cine en Uruguay, pero también los cursos necesarios para el uso de estas máquinas y obviamente la venta de todo tipo de repuestos y accesorios necesarios para el mantenimiento de estos aparatos. Esto parece estar muy claro en el Aviso publicado y firmado por el mismo Comte :

\footnotetext{
"Estando relacionado con Mr. Daguerre quien me instruyó en el manejo de su instrumento y con los mejores ópticos de París que lo fabrican, me hallo en situación de poder proporcionar con todas las modificaciones y mejoras que ha experimentado. A las personas que me favorezcan con su confianza, me obligo a enseñarles su mecanismo y a ponerlos en estado de obtener los resultados más satisfactorios, con una economía considerable de tiempo y trabajo, relativamente al que antes se necesita. Poseyendo el Daguerrotipo simplificado también prevengo a los SRES. que quieran sacar vistas, que me hallo en posición de poder satisfacer sus deseos. También doy clases de dibujo de 7 a 8h1/2 ..buscarme los domingos desde las 11 a las 6 de la tarde, en la casa de M.Isabelle, canciller del Consulado Francés, calle de San Benito. - El Abate Comte" (Duarte Jacinto, 1952 : 117).
}

A esto hay que agregar un segundo punto. La particular situación política en el Rio de la Plata, donde con el bloqueo del puerto de Buenos Aires, Montevideo se confirmaba como una ciudad internacional, refugio de muchos exiliados políticos, bien conectada con Inglaterra, con Francia, con Italia. La pequeña franja de tierra, encajada entre dos gigantes, está amenazada por Argentina, pero estas potencias europeas mantenían el equilibrio político y proporcionaban, pese a la guerra, una actividad mundializada de esta ciudad del Río de la Plata.

Todo esto hacía que Montevideo se convierta en el "centro de un comercio de importación y de exportación" (como bien lo afirma Von Sanden más arriba), donde los negocios y la actividad económica se extendían no solamente en Uruguay sino que dieron origen a una difusión y un comercio regional e internacional importante, participando seguramente al suceso de esta incipiente industria cultural propulsada por el abad y empresario Louis Comte, en estos años de 1840 a 1848 e inclusive al parecer hasta 1865, si atendemos a la fecha donde recibía la última transferencia desde Montevideo. Con la caída del sitio grande el comercio con Buenos Aires se reinicia, abriendo sin duda (de forma distante para el Abate, pero a lo visto de las transacciones, no menos enriquecedora) una etapa más en la expansión de 
sus negocios. El descubrimiento de la cuantiosa herencia dejada por el clérigo, que brindamos en esta nota, podría confirmar estos propósitos.

\section{BIBLIOGRAFÍA}

Arago François, Rapport de M. Arago sur le daguerréotype, lu à la séance de la Chambre des députés, le 3 juillet 1839, et à l'Académie des sciences, séance du 19 août. Bachelier (Paris), 1839, p.52. http://gallica.bnf.fr/ark:/12148/bpt6k1231630.

Avenel, Jean-David. L’Affaire du Rio de la Plata (1838-1852). Economica, 1998.

Broquetas Magdalena, coord. Fotografía en Uruguay: historia y usos sociales, 1840-1930. Montevideo, Uruguay: Centro de Fotografía (Intendencia de Montevideo), 2011.

Carré Adrien, La singulière histoire de l' Oriental-Hydrographe, Bulletin, Comité Nantais de Documentation Historique de la Marine, Nc 2, 1970, pp. 17-35.

Charlety, Sébastien. Histoire de la monarchie de Juillet (1830-1848). Place des éditeurs, 2018.

Duarte Jacinto A., Dos siglos de publicidad en la historia del Uruguay: desde la fundación de Montevideo, 1726-1952, en colaboración con M.Norma Duarte Cattani, Talleres Gráficos Sur, Montevideo,1952, p.117

Gunthert André , Le daguerréotype, première expérience open source, 2006, LHIVIC Actualités de la Recherche en histoire visuelle.

Heffer Jean, Chanut Jean-Marie, Mairesse Jacques. La culture du blé au milieu du XIXe siècle : rendement, prix, salaires et autres coûts. In: Annales. Économies, Sociétés, Civilisations. 41e année, N. 6, 1986. pp. 1273-1302; p.1276

Kossoy, Boris. Fotografia E Historia. Buenos Aires: La Marca Editora, 2003.

La Vouivre du Jura n 25 - 2ème semestre 2007, p.4.

Quarto Convegno dell'Associazione Internazionale Areia "Fotografia e migrazioni" (coordinado por Chiara Vangelista de la Università degli Studi di Genova), 23 febbraio 2018, Università di Ca' Foscari, Venezia (VE). Italia.

Sarmiento Domingo Faustino, Viajes por Europa, África i América, 1845- 1847, Santiago de Chile, Imprenta de Julio Belinycia, 1851, p.23 en línea : https://www.biblioteca.org.ar/libros/70551.pdf

Turazzi Maria Inez, A Viagem do Oriental-Hydrographe (1839-1840) ea Introdução da

Daguerreotipia no Brasil, Revista Acervo, n. 1, v. 23, p. 45-62, 2010.

Turazzi Maria Inez, Máquina viajante. Revista de História (Rio de Janeiro) , v. 52, p. 18-25, 2010.

Turazzi Maria Inez, "El Oriental-Hydrographe y la fotografía / La primera expedición alrededor del mundo con un "arte al alcance de todos" (1839-1840)", Centro de Fotografía (Intendencia de Montevideo), 2019, $400 \mathrm{p}$.

Von Sanden Clara, in Broquetas, Magdalena. Fotografía en Uruguay: historia y usos sociales, 1840-1930. Montevideo, Uruguay: Centro de Fotografía (Intendencia de Montevideo), 2011, p.21. 
Von Sanden, Clara, in Broquetas, Magdalena. Fotografía en Uruguay: historia y usos sociales, 1840-1930. Montevideo, Uruguay: Centro de Fotografía (Intendencia de Montevideo), 2011, p. 18-40.

Wood Derek, The voyage of Captain Lucas and the daguerreotype to Sidney, Journal de la Société des océanistes. 102, 1996-1. pp. 113-118.

\section{NOTAS FINALES}

1. Derek Wood, The voyage of Captain Lucas and the daguerreotype to Sidney, Journal de la Société des océanistes. 102, 1996-1. pp. 113-118.

2. Turazzi Maria Inez, "El Oriental-Hydrographe y la fotografía / La primera expedición alrededor del mundo con un "arte al alcance de todos" (1839-1840)", Centro de Fotografía (Intendencia de Montevideo), 2019, $400 \mathrm{p}$.

3. Quarto Convegno dell'Associazione Internazionale Areia "Fotografia e migrazioni" (coordinado por Chiara Vangelista de la Università degli Studi di Genova), 23 febbraio 2018, Università di Ca' Foscari, Venezia (VE). Italia.

4. Broquetas Magdalena, coord. Fotografía en Uruguay: historia y usos sociales, 1840-1930. Montevideo, Uruguay: Centro de Fotografía (Intendencia de Montevideo), 2011.

5. Todas las remarcas en negrita del texto son nuestras.

6. Este, reconocido geógrafo en Francia, había sido autor del "Atlas élémentaire simplifié de géographie ancienne et moderne" en 1839. Poco tiempo después lo encontramos como profesor de la Escuela Militar y cinco años después se convirtió en el primer director del Observatorio Imperial.

7. " "Aviso". Habiendo sabido que muchas personas, admiradoras del célebre instrumento de M.Daguerre han trepidado en hacerlo venir de Europa por el temor muy fundado de no poderse servir de él y estar privados de los goces que proporciona, tengo el gusto de poner en su conocimiento, que yo me encargaré gustoso de esta comisión. Estando relacionado con M.Daguerre quien me ha instruido en el manejo de su instrumento y con los mejores ópticos de París que la fabrican, me hallo en situación de poderlo proporcionar con todas las modificaciones y mejoras que ha experimentado. A las personas que me favorezcan con su confianza, me obligo a enseñarles su mecanismo y a ponerlos en estado de obtener los resultados mas satisfactorios, con una economía considerable de tiempo y trabajo, relativamente al que antes se necesita.

Poseyendo el Daguerrotipo simplificado también prevengo a los SRES. que quieran sacar vistas, que me hallo en posición de poder satisfacer sus deseos. También doy clases de dibujo de 7 a 8h1/2 ..buscarme los domingos desde las 11 a las 6 de la tarde, en la casa de M.Isabelle, canciller del Consulado Francés, calle de San Benito. » (Aviso El Nacional, Montevideo, 6 de marzo de 1841)

8. Ibid, p.116.

9. Turazzi Maria Inez, A Viagem do Oriental-Hydrographe (1839-1840) ea Introdução da Daguerreotipia no Brasil, Revista Acervo, Jan 1, 2011, p. 45-62. Y en el libro ampliado posterior a nuestro coloquio : Maria Inez Turazzi, "El Oriental-Hydrographe y la fotografía / La primera expedición alrededor del mundo con un "arte al alcance de todos" (1839-1840)", Centro de Fotografía (Intendencia de Montevideo), 2019, $400 \mathrm{p}$.

10. Von Sanden, Clara, in Broquetas, Magdalena. Fotografía en Uruguay: historia y usos sociales, 1840-1930. Montevideo, Uruguay: Centro de Fotografía (Intendencia de Montevideo), 2011, p. 18-40.

11. Broquetas, Magdalena, éd. Fotografía en Uruguay: historia y usos sociales, 1840-1930. Montevideo, Uruguay: Centro de Fotografía (Intendencia de Montevideo), 2011.

12. "De quelle opportunité notre fortuné religieux s'est-il saisi pour venir acquérir dans notre village cette superbe propriété et y vivre ses dernières années? La réponse est pour l'instant en 
suspens mais en venant s'installer à Sampans il apporta avec lui les ferments d'une saga familiale digne des plus beaux romans et qui alimenta sans doute par ses récits épiques les veillées Sampantaises de plusieurs générations. " La Vouivre du Jura $\mathrm{n}^{\circ} 25$ - 2ème semestre 2007, p.4.

13. El precio (según el artículo promocional publicado mas arriba) de la pensión sería de 2.500 francos por año por cada estudiante, incluidas las lecciones, con pensión completa y "formación recibida de profesores de mérito a bordo", de química, física, matemáticas, bellas letras, lenguas modernas y dibujo.

14. Von Sanden, Clara, in Broquetas, Magdalena. Fotografía en Uruguay: historia y usos sociales, 1840-1930. Montevideo, Uruguay: Centro de Fotografía (Intendencia de Montevideo), 2011, p.36.

\section{RESÚMENES}

La introducción del daguerrotipe en América Latina es debida a un abate, Louis Comte quien había navegado a América del Sur en una expedición "L'Orientale" que salió de Francia a fines de septiembre de 1839, quedándose en Montevideo hasta 1848. Pero, a partir de la vuelta del Abate a Europa, perdemos toda traza de él. Este artículo pretende aportar informaciones sobre este período de la historia, gracias al análisis de su legado, donde afirma recibir una importante suma de dinero por medio de una trasferencia desde Montevideo. Terminaremos incursionando en un examen del documento hallado, con el objetivo de profundizar las reflexiones relativas a lo que algunos críticos llaman la primera experiencia "open source", dada la importancia de esta técnica y del estado francés en su impulso.

L'introduction du daguerréotype en Amérique latine est due à un abbé, Louis Comte. Il arrive en Amérique du Sud, lors d'une expédition sur le navire L'Orientale, à la fin de septembre 1839. Il reste à Montevideo jusqu'en 1848. Mais, après le retour de l'abbé en Europe, nous perdons sa trace. Cet article donne des informations sur cette période de l'histoire du prélat, grâce à l'analyse de son héritage, où il prétend recevoir une somme d'argent importante par un transfert de Montevideo. Nous étudierons le document trouvé avec le but d'approfondir les réflexions sur ce que certains critiques appellent la première expérience "open source», compte tenu de l'importance de cette technique et de l'État français dans sa promotion.

\section{ÍNDICE}

Mots-clés: Louis Comte, daguerréotype, testament, photographie en Uruguay, début du cinema en Uruguay

Palabras claves: Louis Comte, daguerrotipo, testamento, fotografía en Uruguay, principios del cine en Uruguay

\section{AUTOR}

EDGARD VIDAL

CNRS-CRAL-CoNRS 